\title{
Posterior cortical atrophy
}

INSERM

\section{Source}

INSERM. (1999). Orphanet: an online rare disease and orphan drug data base. Posterior cortical atrophy. ORPHA:54247

Posterior Cortical Atrophy (PCA) is a rare progressive neurodegenerative disorder with a typical onset between 50-65 years of age characterized by progressive impairment of higher visual processing skills and other posterior cortical functions without any evidence of ocular abnormalities. 